\title{
PELATIHAN CARA PERAWATAN PAYUDARA PADA IBU HAMIL TRIMESTER III DI DESA BANTARJAYA KECAMATAN PEBAYURAN KABUPATEN BEKASI TAHUN 2021
}

\author{
Ika Kania Fatdo Wardani1) \\ 1)Program Studi DIII Kebidanan, Universitas Medika Suherman, Bekasi, Jawa Barat, Indonesia \\ Corresponding author: Ika Kania Fatdo Wardani \\ Email: ikakania34@gmail.com
}

Diterima 18 Oktober 2021, Direvisi 25 Oktober 2021, Disetujui 26 Oktober 2021

\begin{abstract}
ABSTRAK
Data Survei Demografi dan Kesehatan Indonesia tahun 2015 menyebutkan bahwa terdapat ibu nifas yang mengalami Bendungan ASI sebanyak 35.985 atau (15,60\%) ibu nifas (Meihartati, 2017). Hasil studi pendahuluan di Desa Bantarjaya tahun 2021 dengan wawancara dari 10 ibu menyusui, 7 ibu menyusui yang mengalami bendungan ASI dan penyebabnya pada saat hamil dan nifas tidak melakukan perawatan payudara. Perawatan payudara seharusnya dilakukan saat kehamila secara teratur agar produksi ASI saat menyusui cukup. Tujuan kegiatan ini adalah agar ibu hamil bisa melakukan perawatan payudara secara rutin untuk persiapan ibu saat menyusui karena pentingnya ASI maka dilakukan Pelatihan Perawatan Payudara Pada Ibu Hamil Trimester III Di Desa Bantarjaya Kecamatan Pebayuran Kabupaten Bekasi Tahun 2021.Kegiatan dilaksanakan pada hari Jumat 21 Mei 2021, bertempat di Balai Desa Bantar Jaya Kecamatan Pebayuran. Sasaran kegiatan ini adalah ibu hamil trimester III yang bertempat tinggal di Desa Bantar Jaya sebanyak 43 orang. Metode kegiatan yang digunakan dalam pengabdian ini ada berupa pelatihan cara perawatan payudara pada ibu hamil trimester III di Desa Bantarjaya Kecamatan Pebayuran Kabupaten Bekasi tahun 2021. Alat yang digunakan berupa alat peraga (phantom), video cara perawatan payudara, leafleat dan poster yang terkait materi yang akan disampaikan dalam pelatihan tersebut. Hasil nilai pretest dan posttest dari 43 responden memiliki pengetahuan sedang tentang cara perawatan payudara yaitu nilai rata-rata sebesar $75,96 \%$, setelah penyuluhan nilai rata-rata menjadi 90,4\% (Pengetahuan Baik). Berdasarkan nilai pretes dan posttest tersebut ada peningkatan pengetahuan dari responden $(14,34 \%)$. Hasil nilai praktik menunjukkan sebelun dilakukan pelatihan, dari 43 responden memiliki keterampilan yang cukup dalam melakukan perawatan payudara (nilai rata-rata $75,2 \%$ ), setelah evaluasi nilai rata-rata menjadi $97,7 \%$ (Keterampilan Baik). Ada peningkatan keterampilan dari responden setelah evaluasi (22,5\%).Kegiatan pelatihan payudara pada ibu hamil trimester III untuk mempersiapkan ibu hamil dalam pemberian ASI Eksklusif pada masa nifas. Dalam kegiatan ini masih kurangnya pengetahuan dan kemampuan ibu hamil melakukan perawatan payudara. Dengan diadakannya pelatihan cara perawatan payudara bagi ibu hamil trimester III, dapat meningkatkan pengetahuan dan kemampuan ibu hamil dalam melakukan cara perawatan payudara.
\end{abstract}

Kata Kunci : pelatihan; cara perawatan payudara; ibu hamil trimester III

\begin{abstract}
According to the demography survey and Indonesian health in 2015, it stated that there were 35.985 or $(15,60 \%)$ of the postpartum mothers encountered the dam breast milk (Meihartati, 2017). The preliminary study result in Bantar Jaya village, 2021 said that there were 7 out 10 of Breast feeding mothers by interview had the dam breast milk. It was all because when they were pregnant and after the postpartum, they did not do the breast care treatment. In fact, the breast care treatment should be done regularly during the pregnancy in order to produce the enough breast milk. This activity aimed to encourage and support the pregnant women to do the breast care treatment regularly during the pregnancy. It was because breast milk was the important thing after the birth, so it required the training of breast care treatment to the third trimester of pregnant women in Bantar Jaya village Pabayuran district Bekasi regency 2021. The activity was conducted on Friday, $21^{\text {st }} 2021$ in village hall of Bantar Jaya, Pabayuran District. The target activity was 43 of third trimester of pregnant women who lived in Bantar Jaya Village. the method activity of this dedication applied the breast care training to the third trimester of pregnant women in Bantar Jaya Village, Pabayuran district, Bekasi Regency in 2021. The activity instruments were phantom, breast care treatment video, leaflet and poster which were filled by the training materials. The pretest and posttest result score stated that there 43 respondents which had the moderate knowledge of breast care, and it was $75,96 \%$. After the counseling, the 43 respondents'
\end{abstract}


knowledge increased to 90,4\% (good knowledge). Based on the pretest and posttest, there was some enhancement of respondents' knowledge to $14,34 \%$. The practical score showed that before having the counseling, the respondents only got the enough skill to do the breast care (the average score was $75,2 \%$ ). However, after evaluating, the 43 respondents' knowledge increased to 97, 7\% (good skill). Furthermore, there was some skill enhancement of 43 respondents after having the evaluation (22, $5 \%)$. The breast care training activity to third trimester of pregnant women aimed to those pregnant women to get well prepared during pregnancy to do the exclusive breast feeding after the birth. In this activity, previously, they were still lack of breast care knowledge. By having this activity, there was enhancement of knowledge and capability of pregnant women in doing the breast care treatment

Keywords: counseling; breast care treatment; third trimester of pregnant women

\section{PENDAHULUAN}

Data Survey Demografi dan Kesehatan Indonesia tahun 2015 menyebutkan bahwa terdapat ibu nifas yang mengalami Bendungan ASI sebanyak 35.985 atau $(15,60 \%)$ ibu nifas, serta pada tahun 2015 ibu nifas yang mengalami Bendungan ASI sebanyak 77.231 atau (37, $12 \%$ ) ibu nifas (Meihartati, 2017)

Proses menyusui adalah keseluruhan proses menyusui dari ASI di produksi sampai bayi menyusu. Menurut penelitian, anak yang tidak diberi ASI mempunyai IQ (intellectual quotient) lebih rendah 7-8 poin dibandingkan dengan anak yang diberi ASI secara eksklusif. Namun tidak banyak ibu yang bersedia memberikan ASI eksklusif selama 6 bulan seperti disarankan organisasi kesehatan dunia (WHO). Di indonesia rata-rata ibu memberikan ASI eksklusif hanya 2 bulan. Pada saat bersamaan, pemberian susu formula meningkat 3 kali lipat. Saat ini jumlah ibu yang memberikan ASI eksklusif kepada bayinya sampai usia 6 bulan masih rendah, yaitu kurang dari $2 \%$ dari jumlah total ibu melahirkan. (Kristiyanasari, 2011)

Produksi ASI dapat meningkat, salah satunya dipengaruhi oleh cara perawatan payudara. Perawatan payudara adalah tindakan yang dilakukan secara sadar dan teratur untuk memelihara kesehatan payudara. Perawatan payudara penting bagi ibu karena merupakan tindakan tersebut bisa dilakukan oleh klien maupun dibantu oleh orang lain biasanya dilakukan mulai dari hari ke-1 atau ke2 kedua pasca melahirkan (Rosanah, 2015). Tujuannya adalah untuk memperlancar sirkulasi darah serta mencegah sumbatan pada saluran susu, sehingga memperlancar pengeluaran ASI. Produksi ASI dan pengeluaran ASI dipengaruhi oleh dua hormon, yaitu prolaktin dan oksitosin. Prolaktin mempengaruhi jumlah produksi ASI, sedangkan oksitosin mempengaruhi proses pengeluaran ASI (Maritalia, 2012).

Perawatan payudara yang baik dan benar berperan penting dalam meningkatkan produksi ASI dan untuk menghindari dari bahaya pembengkakan payudara, saluran ASI tersumbat (Astutik, 2014). Manfaat Perawatan payudara diantaranya untuk memperlancar sirkulasi darah dan merangsang kelenjarkelenjar air susu sehingga produksi ASI banyak dan lancar, menjaga kebersihan payudara terutama kebersihan putting susu, melenturkan dan menguatkan putting susu sehingga bayi mudah menyusu, dapat mendeteksi kelainankelainan payudara secara dini dan melakukan upaya untuk mengatasinya, mempersiapkan mental (psikis) ibu untuk menyusui (Saryono Pramitasari, 2011).

Berdasarkan hasil studi pendahuluan di Desa Bantarjaya tahun 2021 dengan wawancara didapatkan hasil bahwa dari $10 \mathrm{ibu}$ menyusui, hanya 7 ibu menyusui yang mengalami masalah bendungan ASI dan penyebabnya karena rata-rata dari ibu menyusui tersebut pada saat kehamilan dan nifas tidak melakukan perawatan payudara sehingga terkendala dalam pemberian ASI eksklusif. Perawatan payudara seharusnya dilakukan secara dini (saat kehamilan) secara teratur agar produksi ASI saat menyusui cukup. Tujuan pengabdian masyarakat ini adalah agar ibu hamil bisa melakukan perawatan payudara secara rutin untuk persiapan ibu saat menyusui karena pentingnya ASI dan banyak manfaatnya maka dilakukan Pelatihan Perawatan Payudara Pada Ibu Hamil Trimester III Di Desa Bantarjaya Kecamatan Pebayuran Kabupaten Bekasi Tahun 2021.

\section{METODE}

Kegiatan dilaksanakan pada hari Jumat $21 \mathrm{Mei}$ 2021, bertempat di Balai Desa Bantar Jaya Kecamatan Pebayuran. Sasaran kegiatan ini adalah ibu hamil trimester III yang bertempat tinggal di Desa Bantar Jaya sebanyak 43 orang. Metode kegiatan yang digunakan dalam pengabdian ini adalah berupa pelatihan cara perawatan payudara pada ibu hamil trimester III di Desa Bantarjaya Kecamatan Pebayuran Kabupaten Bekasi tahun 2021. Alat yang digunakan berupa alat peraga (phantom), video cara perawatan payudara, leafleat dan poster 
yang terkait materi yang akan disampaikan dalam pelatihan tersebut.

Kegiatan evaluasi dilaksanakan pada tanggal 31 Mei 2021 pukul 10.00-15.00 WIB dengan sasaran yang sama. Para ibu hamil masingmasing melakukan cara perawatan payudara, kemudian pelaksana mengisi lembar ceklis dari masing-masing responden. Seluruh kegiatan berjalan lancar, semua ibu hamil bisa memahami dan bisa melakukan cara perawatan payudara.

\section{HASIL}

Tabel 1. Rekapitulasi Prosentase Hasil Pelatihan Payudara Pada Ibu Hamil Trimester III

\begin{tabular}{|c|c|c|c|c|c|c|}
\hline Nama & $\begin{array}{l}\text { Nilai } \\
\text { Pretest } \\
\text { (\%) }\end{array}$ & $\begin{array}{l}\text { Nilai } \\
\text { Postes } \\
\text { t (\%) }\end{array}$ & $\begin{array}{l}\text { Peningkat } \\
\text { an } \\
\text { Pengetahu } \\
\text { an (\%) }\end{array}$ & $\begin{array}{l}\text { Nilai } \\
\text { Keterampilan } \\
\text { Sebelum } \\
\text { Pelatihan (\%) }\end{array}$ & $\begin{array}{l}\text { Nilai } \\
\text { keterampilan } \\
\text { Setelah } \\
\text { Pelatihan (\%) }\end{array}$ & $\begin{array}{l}\text { Peningkatan } \\
\text { Nilai Cara } \\
\text { Perawatan } \\
\text { Payudara (\%) }\end{array}$ \\
\hline $\mathrm{R} 1$ & 50 & 66.67 & 16.67 & 50 & 91.67 & 41.67 \\
\hline R2 & 66.67 & 83.33 & 16.66 & 83.33 & 100 & 16.67 \\
\hline R3 & 75 & 100 & 25 & 83.33 & 100 & 16.67 \\
\hline $\mathrm{R} 4$ & 91.67 & 100 & 8.33 & 83.33 & 100 & 16.67 \\
\hline R5 & 91.67 & 100 & 8.33 & 83.33 & 100 & 16.67 \\
\hline R6 & 75 & 91.67 & 16.67 & 83.33 & 100 & 16.67 \\
\hline R7 & 91.67 & 100 & 8.33 & 83.33 & 100 & 16.67 \\
\hline R8 & 83.33 & 91.67 & 8.34 & 83.33 & 100 & 16.67 \\
\hline R9 & 91.67 & 100 & 8.33 & 83.33 & 100 & 16.67 \\
\hline $\mathrm{R} 10$ & 83.33 & 91.67 & 8.34 & 83.33 & 100 & 16.67 \\
\hline $\mathrm{R} 11$ & 75 & 91.67 & 16.67 & 75 & 100 & 25 \\
\hline R12 & 83.33 & 91.67 & 8.34 & 66.67 & 91.67 & 25 \\
\hline R13 & 66.67 & 91.67 & 25 & 75 & 100 & 25 \\
\hline R14 & 75 & 91.67 & 16.67 & 83.33 & 91.67 & 8.34 \\
\hline R15 & 66.67 & 91.67 & 25 & 66.67 & 100 & 33.33 \\
\hline R16 & 83.33 & 91.67 & 8.34 & 83.33 & 91.67 & 8.34 \\
\hline R17 & 50 & 83.33 & 33.33 & 75 & 100 & 25 \\
\hline R18 & 83.33 & 91.67 & 8.34 & 83.33 & 100 & 16.67 \\
\hline R19 & 75 & 83.33 & 8.33 & 83.33 & 100 & 16.67 \\
\hline R20 & 83.33 & 91.67 & 8.34 & 83.33 & 100 & 16.67 \\
\hline R21 & 66.67 & 91.67 & 25 & 83.33 & 100 & 16.67 \\
\hline R22 & 83.33 & 100 & 16.67 & 66.67 & 91.67 & 25 \\
\hline R23 & 75 & 83.33 & 8.33 & 75 & 100 & 25 \\
\hline R24 & 75 & 83.33 & 8.33 & 75 & 100 & 25 \\
\hline R25 & 91.67 & 91.67 & 0 & 75 & 100 & 25 \\
\hline R26 & 83.33 & 100 & 16.67 & 75 & 100 & 25 \\
\hline R27 & 50 & 83.33 & 33.33 & 66.67 & 91.67 & 25 \\
\hline R28 & 83.33 & 100 & 16.67 & 75 & 100 & 25 \\
\hline R29 & 83.33 & 91.67 & 8.34 & 75 & 100 & 25 \\
\hline R30 & 75 & 83.33 & 8.33 & 75 & 100 & 25 \\
\hline R31 & 66.67 & 91.67 & 25 & 66.67 & 100 & 33.33 \\
\hline R32 & 66.67 & 91.67 & 25 & 75 & 91.67 & 16.67 \\
\hline R33 & 66.67 & 83.33 & 16.66 & 66.67 & 100 & 33.33 \\
\hline R34 & 50 & 83.33 & 33.33 & 66.67 & 100 & 33.33 \\
\hline R35 & 83.33 & 91.67 & 8.34 & 66.67 & 91.67 & 25 \\
\hline R36 & 75 & 83.33 & 8.33 & 66.67 & 100 & 33.33 \\
\hline R37 & 75 & 83.33 & 8.33 & 75 & 100 & 25 \\
\hline R38 & 83.33 & 91.67 & 8.34 & 66.67 & 100 & 33.33 \\
\hline R39 & 83.33 & 91.67 & 8.34 & 66.67 & 100 & 33.33 \\
\hline R40 & 66.67 & 91.67 & 25 & 75 & 91.67 & 16.67 \\
\hline R41 & 83.33 & 91.67 & 8.34 & 75 & 91.67 & 16.67 \\
\hline
\end{tabular}




\begin{tabular}{lllllll}
\hline R42 & 75 & 83.33 & 8.33 & 75 & 91.67 & 16.67 \\
\hline R43 & 83.33 & 91.67 & 8.34 & 75 & 91.67 & 16.67 \\
\hline $\begin{array}{l}\text { Rata- } \\
\text { rata }\end{array}$ & $\mathbf{7 5 . 9 6}$ & $\mathbf{9 0 . 4}$ & $\mathbf{1 4 . 3 4}$ & $\mathbf{7 5 . 2}$ & $\mathbf{9 7 . 7}$ & $\mathbf{2 2 . 5}$ \\
\hline
\end{tabular}

Berdasarkan Tabel 1 menunjukkan bahwa sebelum dilakukan penyuluhan, dari 43 responden memiliki pengetahuan sedang tentang cara perawatan payudara yaitu dengan nilai rata-rata sebesar $75,96 \%$, setelah dilakukan penyuluhan dari 43 responden mengalami perubahan nilai rata-rata yaitu sebesar 90,4\% (Pengetahuan Baik). Berdasarkan hasil dari pretes dan posttest tersebut ada peningkatan pengetahuan dari responden, yaitu sebesar $14,34 \%$.

Berdasarkan Tabel 5.1 menungjukkan bahwa sebelun dilakukan pelatihan, dari 43 responden memiliki keterampilan yang cukup dalam melakukan perawatan payudara yaitu dengan nilai rata-rata sebesar $75,2 \%$, setelah dilakukan evaluasi dari pelatihan tersebut dari 43 responden mengalami perubahan nilai rata-rata yaitu sebesar 97,7\% (Keterampilan Baik). Berdasarkan hasil tersebut, ada peningkatan keterampilan dari responden dari sebelum dilakukan pelatihan dengan setelah dilakukan evaluasi yaitu sebesar $22,5 \%$.

\section{PEMBAHASAN}

Hasil kegiatan pengabdian masyarakat ini secara garis besar bertujuan untuk melancarkan produksi ASI dengan cara meningkatkan pengetahuan dan kemampuan ibu hamil trimester III dengan cara melakukan perawatan payudara. Sasaran yang direncanakan sebelumnya adalah ibu hamil trimester III yang ada di Desa Bantarjaya diwilayah kerja puskesmas Pebayuran.

Dalam pelaksanaannya, kegiatan ini diikuti lebih dari 43 ibu hamil trimester III. Peserta tidak hanya pada ibu yang baru pertama hamil. Dengan pengalaman ibu yang pernah menyusui sebelumnya diharapkan ibu yang baru pertama hamil dapat termotivasi untuk memberikan ASI ekslusif bagi anaknya nanti. Hal ini dapat dijadikan sebagai contoh bagi ibu hamil lainnya yang nantinya juga akan menjalani proses menyusui. Ketercapaian target materi pada kegiatan pengabdian masyarakat ini sangat baik, karena materi dapat disampaikan secara keseluruhan meskipun terbagi kedalam beberapa kelompok.

Kemampuan peserta dilihat dari penguasaan materi cukup baik dikarenakan waktu yang berkelanjutan dalam penyampaian materi kepada ibu hamil meskipun kemampuan para peserta berbeda-beda. Secara keseluruhan kegiatan pengabdian masyarakat ini dapat dikatakan berhasil. Keberhasilan ini selain diukur dari keterampilan peserta setelah mengikuti pelatihan dan dari hasil pretest dan posttest yang telah dibagikan. Manfaat yang diperoleh responden adalah dapat mengingat dan mempraktikkan teknik-teknik yang telah diberikan.

Menurut penelitian Darsina yang dilakukan di Puskesmas Meureubo Kabupaten Aceh Barat tahun 2013 menyatakan bahwa ada hubungan antara pengetahuan dan perilaku ibu hamil dalam perawatan payudara. lbu dengan pengetahuan yang baik lebih menyadari bahwa dengan melakukan pemijatan payudara mempunyai manfaat akan memperlancar proses keluarnya air susu ibu.

Penelitian serupa yang dilakukan oleh Ulfah Farrah Lisa di Puskesmas Jeulingke Kecamatan Syiah Kuala Banda Aceh tahun 2018 ada hubungan antara pengetahuan ibu hamil trimester III dengan cara perawatan payudara, karena seorang wanita yang mempunyai pengetahuan yang luas akan lebih tahu manfaat cara perawatan payudara selama masa kehamilan.

\section{SIMPULAN}

Kegiatan pengabdian kepada masyarakat tentang Pelatihan Cara Perawatan Payudara Pada Ibu Hamil Trimester III di Desa Bantarjaya Kecamatan Pebayuran Kabupaten Bekasi Tahun 2021 telah dilaksanakan pada tanggal 21 Mei 2021 mulai pukul 09.00 WIB - 16.00 WIB dengan jumlah peserta yang hadir sebanyak 43 ibu hamil trimester III. Kemudian untuk kegiatan evaluasi dilakukan pada tanggal 31 Mei 2021 pukul 10.00 WIB-15.00 WIB dengan jumlah peserta yang hadir sebanyak 43 ibu hamil responden. Setelah dilakukan evaluasi, ada peningkatan pengetahuan dan keterampilan responden terhadap cara perawatan payudara pada ibu hamil trimester III di Desa Bantarjaya, sehingga pelaksana berharap ibu hamil bisa memberikan ASI ekslusif kepada bayinya nanti pada masa menyusui.

\section{UCAPAN TERIMA KASIH}

Terimakasih kepada Yayasan Medika Bahagia, Para Pimpinan Universitas Medika Suherman, Rekan-rekan Prodi Diploma Tiga Kebidanan yang telah membantu, membimbing dan 
motivasi dalam pelaksanaan kegiatan Pengabdian kepada Masyarakat.

\section{DAFTAR RUJUKAN}

Astutik, R. . (2014). Payudara dan Laktasi. Salemba Medika.

Kristiyanasari. (2011). ASI, Menyusui \& Sadari. Nuha Medika.

Maritalia, D. (2012). Asuhan Kebidanan Nifas dan Menyusui. Pustaka Pelajar.

Meihartati, T. (2017). HUBUNGAN ANTARA PERAWATAN PAYUDARA DENGAN KEJADIAN BENDUNGAN ASI (ENGORGEMENT) PADA IBU NIFAS. Kebidanan Dan Keperawatan, 13 No. 1, 19-24.

Rosanah, H. M. (2015). Ibadah Penuh Berkah Ketika Haid \& Nifas. Lembar Langit Indonesia.

Saryono Pramitasari. (2011). Perawatan Payudara. Mitra Cendekia. 